Article

\title{
The Relationship of the Atlantic Diet with Cardiovascular Risk Factors and Markers of Arterial Stiffness in Adults without Cardiovascular Disease
}

\author{
Carmela Rodríguez-Martín ${ }^{1}$, Luis Garcia-Ortiz ${ }^{1,2}$, Emiliano Rodriguez-Sanchez ${ }^{1}$, \\ Carlos Martin-Cantera $\left.{ }^{3}{ }^{(}\right)$, Alba Soriano-Cano ${ }^{4}$, Maria S. Arietaleanizbeaskoa ${ }^{5}$, \\ Jose F. Magdalena-Belio ${ }^{6}$, Marta Menendez-Suarez ${ }^{7}$, Jose A. Maderuelo-Fernandez ${ }^{1}$,

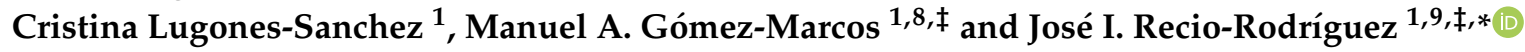 \\ on behalf of the EVIDENT Investigators group
}

1 Institute of Biomedical Research of Salamanca (IBSAL), Primary Health Care Research Unit, La Alamedilla Health Center. Health Service of Castilla y León (SACYL), Primary Care Prevention and Health Promotion Research Network (REDIAPP), 37003 Salamanca, Spain; carmelarroma@hotmail.com (C.R.-M.); lgarciao@usal.es (L.G.-O.); emiliano@usal.es (E.R.-S.); jmaderuelo@saludcastillayleon.es (J.A.M.-F.); crislugsa@gmail.com (C.L.-S.); magomez@usal.es (M.A.G.-M.)

2 Department of Biomedical and Diagnostic Sciences, University of Salamanca, 37008 Salamanca, Spain

3 Primary Health Care Research Unit of Barcelona, Institute IDIAP Jordi Gol, 08007 Barcelona, Spain; 18986cmc@comb.cat

4 Universidad de Castilla-La Mancha, Health and Social Research Center, 16071 Cuenca, Spain; alba.soriano@uclm.es

5 Primary Health Care Research Unit of Bizkaia. Basque Health Service-Osakidetza, 48014 Bilbao, Spain; MARIASOLEDAD.ARIETALEANIZBEASKOASARABIA@osakidetza.eus

6 Torre Ramona Health Center, Aragon Health Service, Instituto de Investigacion Sanitaria IIS-Aragón, 50013 Zaragoza, Spain; jfmagdalenab@gmail.com

7 Casa del Barco Health Center, Castilla and León Health Service, 47007 Valladolid, Spain; martamenendezsuarez@gmail.com

8 Department of Medicine, University of Salamanca, 37008 Salamanca, Spain

9 Department of Nursing and Physiotherapy, University of Salamanca, 37008 Salamanca, Spain

* Correspondence: donrecio@gmail.com; Tel.: +34-923-231859; Fax: +34-923-12364

+ Membership of the EVIDENT Investigators group is provided in the acknowledgments.

$\ddagger$ These two authors contribute equally to this paper.

Received: 5 February 2019; Accepted: 27 March 2019; Published: 29 March 2019

Abstract: Background: Studying the adherence of the population to the Atlantic Diet (AD) could be simplified by an easy and quickly applied dietary index. The aim of this study is to analyse the relationship of an index measuring compliance with recommendations regarding the Atlantic diet and physical activity with cardiovascular disease risk factors, cardiovascular risk factors, obesity indexes and arterial stiffness markers. Methods: We included 791 individuals from the EVIDENT study (lifestyles and arterial ageing), (52.3 \pm 12 years, $61.7 \%$ women) without cardiovascular disease. Compliance with recommendations on $\mathrm{AD}$ was collected through the responses to a food frequency questionnaire, while physical activity was measured by accelerometer. The number of recommendations being met was estimated using a global scale between 0 and 14 points (a higher score representing greater adherence). Blood pressure, plasma lipid and glucose values and obesity rates were measured. Cardiovascular risk was estimated with the Framingham equation. Results: In the overall sample, 184 individuals (23.3\%) scored between $0-3$ on the 14-point index we created, $308(38.9 \%)$ between 4 and 5 points, and $299(37.8 \%) 6$ or more points. The results of multivariate analysis yield a common tendency in which the group with an adherence score of at least 6 points shows lower figures for total cholesterol $(p=0.007)$ and triglycerides $(p=0.002)$. Similarly, overall cardiovascular risk in this group is the lowest $(p<0.001)$, as is pulse wave velocity $(p=0.050)$ and the 
mean values of the obesity indexes studied ( $p<0.05$ in all cases). Conclusion: The rate of compliance with the Atlantic diet and physical activity shows that greater adherence to these recommendations is linked to lower cardiovascular risk, lower total cholesterol and triglycerides, lower rates of obesity and lower pulse wave velocity values.

Keywords: healthy diet; diet; Mediterranean; vascular stiffness; obesity abdominal; risk factors

\section{Introduction}

In recent decades, the study of the effects of nutrition on health has undergone a change in approach, with the focus moving from isolated nutrients to dietary patterns [1]. This change is partly due to the difficulty of studying the effects of individual nutrients since these are consumed as part of a dietary pattern alongside other nutrients, among which complex interactions take place [2-4]. The analysis of a single nutrient in this context may thus be affected by a confounding phenomenon [5] and generate erroneous associations [6]. Some studies complement the analysis of the effect of these dietary patterns on health by analysing the principal component and/or using a cluster analysis. These analyses have been able, for example, to determine that within the concept of a healthy eating pattern, the consumption of a diet rich in cereals, fish, fruit and vegetables is associated with a healthier metabolic profile [7]. They have also allow determining that skipping breakfast or the afternoon snack are risk factors for poor cardiovascular health [8].

Among dietary patterns, the most studied has been the Mediterranean diet and the dietary approaches to stop hypertension (DASH). The Mediterranean diet has shown a reduction in both the incidence and prevalence of chronic diseases like cardiovascular disease, cancer, metabolic syndrome, diabetes, neurodegenerative diseases, as well as a reduction in overall mortality [4]. This diet is considered one of the best dietary patterns in the framework of healthy lifestyle, probably due to the combination of many elements with antioxidant and anti-inflammatory properties [3], thereby constituting a useful tool for the prevention of cardiovascular disease $[2,5,6]$ and making it one of the best analysed in relation to cardiovascular risk and other health outcomes [9]. The DASH dietary pattern, was originally developed to treat hypertension without medication and was associated with substantially lower risk of coronary artery disease and stroke mortality and other cardiometabolic advantages [10-12].

However, more recently, a pattern known as the Atlantic Diet (AD), representative of the traditional diet of Portugal and Galicia (Northwest Spain) has been focusing the attention. Although it has many elements in common with the Mediterranean diet (consumption of fruits and vegetables, nuts and olive oil) and with the DASH dietary pattern (fruits, vegetables nuts, legumes or moderate consumption of low fat dairy), the AD has some differentiating characteristics such as the increased intake of fish and seafood, potatoes, broths with meat and cabbage, and moderate consumption of lean meats [13]. To date, while available evidence regarding this dietary pattern is not particularly extensive, published scientific studies have shown that it can provide important health benefits. In a case-control study conducted in 2010 in Porto by Oliveira et al. [14], an inverse association between adherence to $\mathrm{AD}$ and a lower probability of non-fatal myocardial infarction was reported. Guallar-Castillon et al. [15], examined the association between Southern European AD (SEAD) and various biomarkers of coronary risk, blood pressure and anthropometry. Greater adherence to the SEAD was associated with lower levels of C-reactive protein in plasma, plasma triglycerides, insulin resistance index, albumin in urine, urine albumin-creatinine ratio, and systolic blood pressure.

Studying the adherence of the population to this dietary pattern and its relationship with cardiovascular disease, as well as possible comparisons with other dietary patterns, could be simplified by an easy and quickly applied dietary index. The aim of this study is to develop a dietary index, based on a food frequency questionnaire, which would allow a quick and easy assessment of compliance 
with the recommendations regarding the Atlantic diet and physical activity and an analysis of its association with cardiovascular disease risk score as primary outcome and cardiovascular risk factors, obesity indexes and arterial stiffness markers as secondary outcomes.

\section{Materials and Methods}

\subsection{Study Design}

The results of this study are a subanalysis of the EVIDENT 2 study (Lifestyles and arterial aging). This article presents the data from the baseline assessment alone. The EVIDENT 2 study protocol [16], with a description of data gathering methods, has been published previously. The EVIDENT 2 was a multi-centre clinical trial aiming to assess the effect of a smartphone application with brief counselling on improving the lifestyles in the general population.

\subsection{Study Population}

The EVIDENT 2 study participants were selected through random sampling from offices of general practitioners in six health centers from Spain. For this analysis, among the 833 participants in the EVIDENT 2 study, we included a total of 791 individuals. The remaining 42 participants did not have valid dietary records at the baseline assessment visit and collected using a food frequency questionnaire (FFQ). Other measures included in this study (cardiovascular risk factors and obesity indexes) were present on the 791 participants included. Exclusion criteria were as follows: being over 70 years of age, having cardiovascular disease, heart failure, moderate or severe chronic obstructive pulmonary disease, musculoskeletal disease which prevented walking, advanced liver, lung or kidney disease, severe mental illness, oncological disease treated and diagnosed in the 5 years prior to the beginning of the study, terminal illness, and pregnancy.

\subsection{Ethics Approval and Consent to Participate}

The study was approved by the clinical research ethics committee (CEIC) of the health care area of Salamanca ("CEIC of Area de Salud de Salamanca", 21 June 2013) as a coordinating centre. It was also approved by the ethics committees of the five collaborating centres ("CEIC of Aragón (CEICA), CEIC of IDIAP Jordi Gol, CEIC of Euskadi (CEIC-E), CEIC of Castilla la Mancha and CEIC of the Area de Salud de Valladolid Oeste"). Subjects signed informed consent forms prior to inclusion in the study, in accordance with the Declaration of Helsinki. Trial registration: ClinicalTrials.gov Identifier: NCT02016014

\subsection{Variables and Measuring Instruments}

Assessment of compliance with recommendations on the Atlantic diet and physical activity: Dietary intake was collected by means of a semiquantitative, self-administered food frequency questionnaire (FFQ), using the previous year as the reference period. This questionnaire has been validated for energy, nutrient intake and food groups, against three-day dietary records in Spain [17] and includes 137 foods frequently used among the reference population. After receiving instructions from the study staff, participants indicated the frequency with which each food item was consumed over the last year using a Likert scale of nine options (never or almost never, 1-3 times a month, once a week, 2-4 times a week, 5-6 times a week, once a day, 2-3 times a day, 4-6 times a day or more than 6 times a day). Based on the results, we estimated the daily energy consumption (kcal), as well as the daily intake of macro and micronutrients (g). With the data of the FFQ, we have calculated an index of adherence to the Atlantic Diet, adapting the recommendations provided by Oliveira et al. [14], Calvo-Malvar et al. [18] and Vaz Velho et al. [13]. Oliveira et al. [14] developed an index based on a food frequency questionnaire. This index consists of nine food groups (fresh fish, dried salt cod, red meat and pork products, dairy products, legumes and vegetables, vegetable soup, potatoes, whole-grain bread, and wine). Subsequently, Calvo-Malvar et al. [18] established a series of recommendations for 
good compliance with this dietary pattern which, in addition to previous ones, included olive oil, fruit, eggs, nuts and other additional items to reduce the consumption of foods rich in animal fats, sweets or sugar-sweetened beverages. Finally, Vaz Velho [13], and Tojo et al. [19] included in the AD pyramid performing daily physical activity moderate to high intensity. All these recommendations were put together for the calculation of a 14-item index (Table 1). Compliance with each of the criteria defined in Table 1 scored one point, with the overall score ranging from 0 to 14 points (the higher the score, the greater the adherence). After the calculation of the index, the sample has been divided into 3 groups, using the integer values closest to the tertiles according to the number of $\mathrm{AD}$ recommendations met ( $0-3$ points, $4-5$ points and $\geq 6$ points).

Table 1. Composition of the ATLANTIC diet and lifestyle index.

\begin{tabular}{|c|c|c|}
\hline Components & Frequency & Servings Equivalents \\
\hline Fresh fruit & $\geq 3$ servings/day & 1 serving: 1 piece or serving \\
\hline Vegetables & $\geq 2$ servings/day & 1 serving: $200 \mathrm{~g}$ \\
\hline Fish and seafood & $\geq 3$ servings/week & 1 serving: $130 \mathrm{~g}$ fish, $200 \mathrm{~g}$ seafood \\
\hline Lean meat & $\geq 3$ servings/week & 1 serving: $130 \mathrm{~g}$ \\
\hline Eggs & $\geq 3$ servings/week & 1 serving: quantity 1 \\
\hline Pulses & $\geq 2$ servings/week & 1 serving: $150 \mathrm{~g}$ \\
\hline Sweets, pastries, cakes, candies, ice cream & $\leq 4$ servings/month & $\begin{array}{c}1 \text { serving: } 50 \text { g sweets, pastries or cakes, ice } \\
\text { cream quantity } 1\end{array}$ \\
\hline Sugar-sweetened beverages & $\leq 4$ servings/month & 1 serving: $200 \mathrm{cc}$ \\
\hline Moderate and or vigorous physical activity & $\geq 60 \mathrm{~min} /$ day & \\
\hline \multicolumn{3}{|c|}{ Each issue scored with one point if it is met } \\
\hline
\end{tabular}

Assessment of habitual physical activity: Physical activity was measured using GT3X accelerometers, previously validated [20]. Data collected includes time spent daily (min/day) on moderate-vigorous activities. The device was worn for seven consecutive days.

Assessment of cardiovascular risk factors: For blood pressure, three readings were taken on each arm, using the mean of the last two from the arm with the highest values. Measurements were obtained with an oscillometric device, OMRON M10-IT (Omron Health Care, Kyoto, Japan), following the recommendations of the European Hypertension Society [21]. For the analysis of the laboratory variables, a blood sample was taken after a 12 - $\mathrm{h}$ fast. The following values of plasma glucose, hemoglobin $\mathrm{A} 1 \mathrm{c}(\mathrm{HbA} 1 \mathrm{c})$ and lipid profile were measured: total plasma cholesterol, high density lipoprotein cholesterol (HDL-C) and triglycerides. Low density lipoprotein cholesterol (LDL-C) was estimated using the Friedewald equation except in subjects who had triglyceride levels $\geq 300 \mathrm{mg} / \mathrm{dL}$ $(n=10)$, in which case we used $299 \mathrm{mg} / \mathrm{dL}$ for the calculation of triglycerides. Hypertension was recorded with systolic blood pressure values of $\geq 140 \mathrm{mmHg}$ and/or diastolic blood pressure values of $\geq 90 \mathrm{mmHg}$ or if the subject was on antihypertensive medication [22]. Type 2 diabetes mellitus was present with $\mathrm{HbA} 1 \mathrm{c} \geq 6.5 \%$, fasting plasma glucose $\geq 126 \mathrm{mg} / \mathrm{dL}, 2 \mathrm{~h}$ of plasma glucose $\geq 200 \mathrm{mg} / \mathrm{dL}$ during an oral glucose tolerance test, or random plasma glucose $\geq 200 \mathrm{mg} / \mathrm{dl}$ for a patient with classic symptoms of hyperglycemia or hyperglycaemic crisis or under antidiabetic treatment [23]. Information regarding drugs used for hypertension, type 2 diabetes and dyslipidemia was gathered by accessing data from the electronic medical records and then confirmed by the subjects themselves. Smoking 
history was assessed through questions about the participant's smoking status (smoker/non-smoker). We considered smokers to be subjects who currently smoke or who stopped smoking less than one year ago.

Cardiovascular risk assessment (CVR): This was estimated using the published risk equation based on the Framingham study [24] to assess general cardiovascular disease risk and 10-year risk of individual cardiovascular events (coronary, cerebrovascular, and peripheral arterial disease and heart failure). Risk factors used include age, total cholesterol, high-density lipoprotein cholesterol and SBP as quantitative variables, and gender, drug treatment for hypertension, smoking and history of diabetes mellitus as dichotomous variables. The 791 participants who meet the selection criteria allow detecting a minimum difference in cardiovascular risk of three percentage points between two of the three groups into which we have classified AD adherence, assuming an alpha risk of 0.05 and a beta risk of 0.2 in bilateral contrast. This minimum difference was based on the results found after a diet and aerobic exercise program intervention, which achieved a reduction of 3.0 points on cardiovascular risk [25].

Anthropometric variables: Body weight was measured twice with an approved electronic scale (Seca 770, Medical Scale and Measurement Systems, Birmingham, UK) after calibration (accuracy $\pm 0.1 \mathrm{~kg}$ ), with readings rounded to $100 \mathrm{~g}$. Height was measured with a stadiometer (Seca 222, Medical Scale and Measurement Systems, Birmingham, UK), recording the average of two measurements. Body mass index (BMI) was calculated using the formula weight (kg) divided by height squared $\left(\mathrm{m}^{2}\right)$. Waist and hip circumference were measured using a flexible tape measure following the recommendations of the Spanish Society for the Study of Obesity in 2007 [26]. All measurements were taken with the patient standing, barefoot and in light clothing. With these values, the waist-height index and the waist-hip index were subsequently calculated by means of the ratio of waist circumference to height or hip circumference, respectively. The adiposity index was based on the equation (Adiposity index $=(($ hip circumference $) /($ height $) \times(1.5))-18))[27]$.

Analysis of pulse wave velocity (PWV): Pulse wave velocity was recorded in the Salamanca cohort $(n=291)$. This cohort had similar age and gender distribution to that the entire sample. The measurement was made with the patient in supine position using the SphymgoCor System (AtCor Medical Pty Ltd. Head Office, West Ryde, Australia), following the recommendations of the Van Bortel et al. consensus [28]. The pulse waves of the carotid and femoral arteries were analysed, and the delay was estimated with respect to the ECG wave. A tape measure was used to determine the distance from the sternal fork to the carotid and femoral artery sensor locations. Velocity was estimated in $\mathrm{m} / \mathrm{second}$.

\subsection{Statistical Analysis}

Results are expressed as means \pm standard deviation for quantitative variables and by frequency distribution in the case of qualitative variables. The differences of means for continuous variables across the three groups were assessed through one-way analysis of variance (ANOVA) for independent samples, using the DMS method in post-hoc contrasts. An analysis of the covariance (ANCOVA) was also carried out, including as an independent variable the Atlantic diet and lifestyle index divided into the three categories described above, and as dependent variables cardiovascular risk, blood pressure, cholesterol, triglycerides, glucose, pulse wave velocity and anthropometric markers such as BMI, adiposity index, waist/height and waist/hip ratio. This analysis was adjusted only for the energy intake in the case of the cardiovascular risk to avoid collinearity. For the rest of the dependent variables, the analysis was controlled for age, gender and calorie intake (kcal) in all models, for the use of antihypertensive drugs in the case of blood pressure, for lipid-lowering drugs in the case of cholesterol and triglycerides, for antidiabetics in the case of glucose, and for antihypertensive drug treatment, blood pressure and smoking status in the pulse wave velocity analysis. Statistical analysis was performed with IBM SPSS Statistics for Windows, Version 23.0. (Armonk, NY, USA: IBM Corp.). A $p$ value of $<0.05$ was considered statistically significant. 


\section{Results}

Of the 791 individuals selected ( $52.3 \pm 12$ years, $61.7 \%$ women), $33.1 \%$ were hypertensive and $7.3 \%$ had type 2 diabetes mellitus (Table 2). The scores on the 14-point index scale of the total sample were as follows: 184 participants (23.3\%) registered 0-3, 308 (38.9\%) between 4 and 5 points, and 299 (37.8\%) 6 or more points. The average index score assessing AD adherence was 4.9 points \pm 1.7 . Among the 14 items proposed, the one with the highest level of adherence $(90.5 \%)$ was the consumption of at least three servings per week of fish or seafood. Conversely, the consumption of at least six servings/day of bread, cereals, wholegrain cereals, rice, pasta and potatoes was the item with the lowest compliance percentage $(2.8 \%)$ (Table 3$)$.

Table 2. Baseline characteristics and clinical characteristics of the study population.

\begin{tabular}{|c|c|}
\hline Measures & Overall $(n=791)$. Mean or $n($ SD or $\%)$ \\
\hline Age (years) & $52.3(12.0)$ \\
\hline Gender, Female $(n, \%)$ & $488(61.7)$ \\
\hline Hypertension $(n, \%)$ & $262(33.1)$ \\
\hline Diabetes $(n, \%)$ & $58(7.3)$ \\
\hline Antihypertensive agents $(n, \%)$ & $193(24.4)$ \\
\hline Hypoglycemic agents $(n, \%)$ & $50(6.3)$ \\
\hline Lipid-lowering agents $(n, \%)$ & $155(19.6)$ \\
\hline $\mathrm{SBP}(\mathrm{mmHg})$ & $123.9(16.1)$ \\
\hline $\mathrm{DBP}(\mathrm{mmHg})$ & $76.2(9.8)$ \\
\hline Heart rate (bpm) & $70.9(11.5)$ \\
\hline Glycated hemoglobin (\%) & $5.5(0.6)$ \\
\hline Serum glucose (mg/dL) & $90.2(17.5)$ \\
\hline Total cholesterol (mg/dL) & $204.0(36.0)$ \\
\hline HDL-cholesterol (mg/dL) & $58.7(15.1)$ \\
\hline LDL-cholesterol (mg/dL) & $124.5(31.6)$ \\
\hline Tryglicerides (mg/dL) & $110.4(65.8)$ \\
\hline Fibrinogen (mg/dL) & $358.9(85.1)$ \\
\hline $\mathrm{BMI}\left(\mathrm{kg} / \mathrm{m}^{2}\right)$ & $27.8(4.9)$ \\
\hline Waist circumference $(\mathrm{cm})$ & $95.1(13.1)$ \\
\hline Hip circumference $(\mathrm{cm})$ & $105.0(9.4)$ \\
\hline Waist-height ratio & $0.58(0.78)$ \\
\hline Waist-hip ratio & $0.91(0.10)$ \\
\hline Adiposity index & $27.6(6.4)$ \\
\hline CVR & $10.1(10.4)$ \\
\hline Moderate and or vigorous physical activity (min/day) & $65.0(30.9)$ \\
\hline
\end{tabular}

Categorical variables are expressed as $n(\%)$ and continuous variables as mean \pm standard deviation (SD). SBP: Systolic blood pressure; DBP: Diastolic blood pressure; HDL: High-density lipoprotein cholesterol; LDL: Low-density lipoprotein cholesterol; BMI: Body mass index; CVR: Cardiovascular risk; cfPWV: Carotid femoral pulse wave velocity. 
Table 3. Adherence to the ATLANTIC diet and lifestyle index.

\begin{tabular}{|c|c|}
\hline Atlantic Diet Adherence Items & $n(\%)$ \\
\hline Bread, cereals, wholegrain cereals, rice, pasta and potatoes ( $\geq 6$ servings/day) & $22(2.8)$ \\
\hline Olive oil ( $\geq 3$ servings / day) & $195(24.7)$ \\
\hline Fresh fruit ( $\geq 3$ servings / day) & $253(32.0)$ \\
\hline Vegetables ( $\geq 2$ servings/day) & $362(45.8)$ \\
\hline Dairy products ( $\geq 3$ servings / day) & $265(33.5)$ \\
\hline Fish and seafood ( $\geq 3$ servings/week) & $716(90.5)$ \\
\hline Lean meat ( $\geq 3$ servings/week) & $513(64.9)$ \\
\hline Eggs ( $\geq 3$ servings/week) & $47(5.9)$ \\
\hline Pulses ( $\geq 2$ servings/week) & $71(9.0)$ \\
\hline Nuts, preferably chestnuts, walnuts, almonds and hazelnuts ( $\geq 4$ servings/week) & $195(24.7)$ \\
\hline Fatty meat, cured sausage, margarine, butter ( $\leq 4$ servings/month) & $71(9.0)$ \\
\hline Sweets, pastries, cakes, candies, ice cream ( $\leq 4$ servings /month) & $144(18.2)$ \\
\hline Sugar-sweetened beverages ( $\leq 4$ servings/month) & $596(75.3)$ \\
\hline Moderate and or vigorous physical activity ( $\geq 60 \mathrm{~min} /$ day) & $409(51.7)$ \\
\hline
\end{tabular}

There are differences between the three groups with respect to energy consumption (kcal). The diet of the group with the highest adherence ( 6 points or more) has more calories, together with a lower percentage of saturated fat and a higher percentage of proteins, with the total amount of fat being similar to that consumed in the other groups (Table 4).

Table 4. Energy intake and daily nutrients intake by score of ATLANTIC diet and lifestyle index.

\begin{tabular}{|c|c|c|c|c|c|}
\hline & $\begin{array}{c}\text { Overall } \\
(n=791) \\
\text { Mean or } n \\
(\mathrm{SD} \text { or } \%)\end{array}$ & $\begin{array}{c}0-3 \text { Points } \\
(n=184) \\
\text { Mean or } n \\
(\text { SD or } \%)\end{array}$ & $\begin{array}{l}4-5 \text { Points } \\
(n=308) \\
\text { Mean or } n \\
(\text { SD or } \%)\end{array}$ & $\begin{array}{l}\geq 6 \text { Points } \\
(n=299) \\
\text { Mean or } n \\
(\text { SD or } \%)\end{array}$ & $p$ Value \\
\hline Energy intake (kcal/day) *\#\& & 2477 (786) & $2103(600)$ & 2447 (759) & 2738 (816) & $<0.001$ \\
\hline Carbohydrate $(\%) *$ & $42.3(7.0)$ & $43.4(6.8)$ & $41.8(6.9)$ & $42.3(7.1)$ & 0.046 \\
\hline Protein $(\%) * \# \&$ & $17.7(3.3)$ & $16.7(2.9)$ & $17.5(3.4)$ & $18.4(3.3)$ & $<0.001$ \\
\hline Total fat $(\%)$ & $37.5(6.4)$ & $37.0(6.1)$ & $38.0(6.3)$ & $37.3(6.7)$ & 0.219 \\
\hline Saturated fat $(\%) * \#$ & $10.9(2.5)$ & $11.5(2.5)$ & $11.0(2.5)$ & $10.4(2.4)$ & $<0.001$ \\
\hline Fiber (g/day) ${ }^{*} \& \&$ & $27(11)$ & $20(6)$ & $26(9)$ & $34(11)$ & $<0.001$ \\
\hline Cholesterol (g/day) *\#\& & 460 (177) & $388(151)$ & $462(173)$ & $503(182)$ & $<0.001$ \\
\hline
\end{tabular}

Categorical variables are expressed as $n(\%)$ and continuous variables as mean \pm standard deviation. p: statistically significant differences $(p<0.05)$; Post-hoc contrasts (DMS): ${ }^{*}$ Between $0-3$ and 4-5 points, \# Between 0-3 and $\geq 6$ points, \& Between $4-5$ and $\geq 6$ points.

In terms of groups, the one comprising individuals with an $\mathrm{AD}$ adherence score of at least 6 points was characterized by being older (55.1 years) and having a higher percentage of women $(68.9 \%)$ among them. In an unadjusted model, no differences were found between the groups with different $\mathrm{AD}$ adherence in either the variables related to cardiovascular risk factors or in the use of drugs. No differences were found in the figures for blood pressure or metabolic control, nor in the global values of cardiovascular risk or carotid-femoral pulse wave velocity. However, the group with the highest adherence showed lower levels of plasma triglycerides, as well as lower BMI and waist circumference values (Table 5). 
Table 5. Cardiovascular risk, mean cardiovascular risk factors and obesity indexes by score of ATLANTIC diet and lifestyle index. ${ }^{\text {a }}$

\begin{tabular}{|c|c|c|c|c|c|c|c|c|c|c|}
\hline & \multicolumn{5}{|c|}{ Unadjusted Means } & \multicolumn{5}{|c|}{ Adjusted Means ${ }^{b}$} \\
\hline & $\begin{array}{c}0-3 \text { Points } \\
(n=184) \\
\text { Mean or } n \\
(\text { SD or } \%)\end{array}$ & $\begin{array}{l}\text { 4-5 Points } \\
(n=308) \\
\text { Mean or } n \\
(\text { SD or } \%)\end{array}$ & $\begin{array}{l}\geq 6 \text { Points } \\
(n=299) \\
\text { Mean or } n \\
(\text { SD or } \%)\end{array}$ & $p$ Trend & & $\begin{array}{c}0-3 \text { Points } \\
(n=184) \\
\text { Mean or } n \\
(\text { SD or } \%)\end{array}$ & $\begin{array}{l}\text { 4-5 Points } \\
(n=308) \\
\text { Mean or } n \\
(\text { SD or } \%)\end{array}$ & $\begin{array}{l}\geq 6 \text { Points } \\
(n=299) \\
\text { Mean or } n \\
(\text { SD or } \%)\end{array}$ & $p$ trenc & \\
\hline CVR & $10.2(11.1)$ & $9.4(9.0)$ & $10.6(11.2)$ & 0.377 & & $12.6(9.0)$ & $9.7(8.6)$ & $8.8(8.9)$ & $<0.001$ & *\# \\
\hline C SBP $(\mathrm{mmHg})$ & $123.5(18.2)$ & $124.3(14.8)$ & $123.6(16.2)$ & 0.829 & & $124.3(14.4)$ & $124.5(13.7)$ & $122.9(14.3)$ & 0.344 & \\
\hline Serum glucose $(\mathrm{mg} / \mathrm{dL})$ & $90.4(18.6)$ & $90.0(17.8)$ & $90.3(16.5)$ & 0.970 & & $90.9(14.7)$ & $90.8(14.0)$ & $89.2(14.6)$ & 0.326 & \\
\hline Total cholesterol (mg/dL) & $199.0(32.9)$ & $208.4(37.1)$ & $202.5(36.0)$ & 0.013 & $* \&$ & $203.1(36.8)$ & $208.7(34.6)$ & $199.7(36.2)$ & 0.007 & $\&$ \\
\hline Tryglicerides (mg/dL) & $122.7(70.5)$ & $112.9(77.4)$ & $100.3(45.0)$ & $<0.001$ & $\# \&$ & $122.6(67.8)$ & $113.3(63.9)$ & $99.9(67.0)$ & 0.002 & $\# \&$ \\
\hline Fibrinogen $(\mathrm{mg} / \mathrm{dL})$ & $355.9(90.2)$ & $356.4(87.1)$ & $363.3(79.7)$ & 0.572 & & $363.3(94.5)$ & $356.7(88.4)$ & $358.3(93.6)$ & 0.744 & \\
\hline $\operatorname{cfPWV}(\mathrm{m} / \mathrm{s}) n=291$ & $7.1(1.6)$ & $7.1(1.3)$ & $7.4(1.3)$ & 0.166 & & $7.4(5.5)$ & $7.2(5.2)$ & $7.2(5.5)$ & 0.050 & *\# \\
\hline $\operatorname{BMI}\left(\mathrm{kg} / \mathrm{m}^{2}\right)$ & $28.3(5.6)$ & $28.2(5.0)$ & $27.2(4.2)$ & 0.016 & \#\& & $28.6(5.0)$ & $28.2(4.7)$ & $27.0(5.0)$ & 0.001 & $\# \&$ \\
\hline Waist-height ratio & $0.58(0.08)$ & $0.59(0.08)$ & $0.58(0.07)$ & 0.184 & & $0.59(0.08)$ & $0.59(0.07)$ & $0.57(0.08)$ & 0.001 & $\# \&$ \\
\hline Waist-hip ratio & $0.91(0.10)$ & $0.91(0.11)$ & $0.90(0.08)$ & 0.211 & & $0.91(0.08)$ & $0.91(0.09)$ & $0.90(0.09)$ & 0.121 & \\
\hline Adiposity index & $27.1(6.7)$ & $28.0(6.8)$ & $27.3(5.8)$ & 0.252 & & $28.2(6.3)$ & $28.1(6.0)$ & $26.6(6.3)$ & 0.004 & $\# \&$ \\
\hline
\end{tabular}

${ }^{a}$ Results are reported as mean \pm standard deviation. p: statistically significant differences $(p<0.05)$. Post-hoc contrasts (DMS): * Between $0-3$ and $4-5$ points, \# Between $0-3$ and $\geq 6$ points, \& Between $4-5$ and $\geq 6$ points, ${ }^{b}$ Adjusted means for age, gender and total energy intake by analysis of covariance (ANCOVA). Model for SBP adjusted, also for antihypertensive drugs.

Model for serum glucose adjusted, also, for antidiabetic drugs. Model for tryglicerides and total cholesterol adjusted, also, for lipid-lowering drugs. Model for the pulse wave velocity analysis adjusted, also, for antihypertensive drug treatment, blood pressure and smoking status. Model for CVR adjusted only for energy intake. ${ }^{\mathrm{c}}$ SBP: Systolic blood pressure; CVR:

Cardiovascular risk; cfPWV: Carotid femoral pulse wave velocity; BMI: Body mass index. 
In the adjusted model, controlling for potential confounding variables, the multivariate analysis yields a common tendency in which the group of those adhering to at least 6 points in the adherence index show lower total cholesterol figures $(p=0.007)$, and triglycerides $(p=0.002)$. Systolic blood pressure and glucose follow the same trend, without reaching statistical significance. Similarly, their overall cardiovascular risk is the lowest $(p<0.001)$, as is their pulse wave velocity figure $(p=0.050)$ (Table 5). Also, higher compliance with AD items is associated with lower figures of body mass index, waist circumference and waist-height index.

\section{Discussion}

Developed from a food frequency questionnaire, the index created to assess the Atlantic Diet (AD) and lifestyle allows adherence to the recommendations described for this dietary pattern to be quantified. The main results show that greater compliance with these recommendations is associated with lower cardiovascular risk and lower figures for some cardiovascular risk factors such as cholesterol and triglycerides. Likewise, a higher score in this index is linked to lower figures in all the anthropometric markers studied. Finally, this study explores for the first time the relationship between this dietary pattern and arterial stiffness, showing an inverse relationship between them. The higher the level of adherence, the lower the pulse wave velocity.

The study of the health effects of certain dietary patterns requires valid instruments which are easy to administer in clinical practice. The PREDIMED study group (Effects of the Mediterranean diet in the primary prevention of cardiovascular disease) developed a questionnaire of 14 items [29] to assess the adherence to the Mediterranean Diet which has been used in innumerable subsequent studies. This questionnaire correlated very strongly with a food frequency questionnaire [29]. However, although AD has also been observed to have significant positive effects on health, there is no widely used questionnaire to assess compliance with its recommendations. The index created by our group, presented in this manuscript, includes all these recommendations, adapting the responses to a food frequency questionnaire widely used in other research [30,31]. The composition and validation of an $\mathrm{AD}$ adherence questionnaire using this index may be of interest in initiating a debate in which both dietary patterns (Mediterranean and Atlantic) can be compared in terms of predicting cardiovascular disease.

To date, not a great deal of evidence has been generated regarding the relationship of the AD dietary pattern with health. The work of Guallar-Castillon et al. [15] has yielded the most outstanding results. This study used the nine-component index, which we described in the previous paragraph, finding an average compliance of 2.9 points out of 9 possible pints among the 10,231 individuals studied. This represents relatively low adherence to $\mathrm{AD}$ and coincides with that found in the EVIDENT study (4.9 points \pm 1.7 ) out of 14 possible points. Both studies concur in that greater compliance with the recommendations of this dietary pattern is related to lower values for blood pressure or plasma levels of cholesterol and triglycerides. However, the EVIDENT study is the first to explore the possible association with global cardiovascular risk, calculated by a risk equation. Among the possible explanations for the results found in this study, we can point out that individually, many of the components of $\mathrm{AD}$ have been associated with cardiovascular disease, including the clearest distinguishing aspect with respect to the Mediterranean diet or the DASH diet, which is a high consumption of fish [32]. The creation of this index allows measuring the combined effect of all these components, as well as their possible interactions, on cardiovascular risk or cardiovascular risk factors. Oliveira et al. [14] concluded that adherence to AD was associated with a lower probability of non-fatal myocardial infarction. These results could potentially be explained by the possible relationship indicated in this study, considering carotid-femoral pulse wave velocity, a marker of arterial stiffness, as a surrogate marker in the development of cardiovascular disease [33]. These results may therefore be the beginning of a line of research on the effects of AD in subclinical atherosclerosis assessed through arterial stiffness. Furthermore, the association of the AD index with the anthropometric markers exploring both general obesity (BMI, adiposity index) and abdominal obesity (waist-hip 
index and waist-height index) is also of relevance. This relationship may be mediated by the increase in some inflammatory markers such as insulin resistance or C-reactive protein [15]. The GALIAT clinical trial [18] will clarify these issues as it is the first clinical trial to analyse the effects of AD on adiposity markers.

The present study presents a series of limitations. The design of the study (being cross-sectional) does not allow causal relationships to be established between compliance with the recommendations of the AD and the variables studied, but it may be useful when proposing intervention or longitudinal studies to clarify the role of this dietary profile on health like those developed for the DASH diet or the Mediterranean diet. The AD index was created using the responses of the participants to a food frequency questionnaire which was previously validated in the reference population (Spanish population). Some studies indicate that FFQ may overestimate food consumption compared to other assessment instruments [34-36]. The population used for the analysis presented comprised participants of a clinical trial (EVIDENT 2), the aim of which was to measure the effectiveness of using a smartphone application in the improvement of lifestyles. However, the data used from the food frequency questionnaire are those corresponding to the first baseline assessment visit, at which stage no intervention of any kind had yet been carried out.

\section{Conclusions}

Based on the rate of compliance with the Atlantic diet and the lifestyle, developed from a food frequency questionnaire, the main results show that greater compliance with these recommendations is related to lower cardiovascular risk and lower average values for cholesterol and triglycerides, lower rates of obesity and lower figures for pulse wave velocity.

Author Contributions: Conceptualization, J.I.R.-R., C.R.-M., M.A.G.-M. and L.G.-O.; Methodology, J.I.R.-R., C.R.-M., M.A.G.-M. and L.G.-O.; Formal Analysis, L.G.-O., J.A.M.-F., C.R.-M., M.A.G.-M. and J.I.R.-R.; Investigation, J.I.R.-R, C.R.-M., E.R.-S., C.M.-C., A.S.-C., M.S.A., J.F.M.-B., M.M.-S., C.L.-S.; Resources, J.I.R.-R., C.R.-M., E.R.-S., C.M.-C., A.S.-C., M.S.A., J.F.M.-B., M.M.-S., C.L.-S.; Data Curation J.I.R.-R., C.R.-M., E.R.-S., C.M.-C., A.S.-C., M.S.A., J.F.M.-B., M.M.-S., C.L.-S.; Writing-Original Draft Preparation, J.I.R.-R., L.G.-O., M.A.G.-M. and C.R.-M.; Writing-Review \& Editing, all the authors; Visualization, J.I.R.-R.; Supervision, J.I.R.-R.; Project Administration, J.I.R.-R. and M.A.G.-M.; Funding Acquisition, L.G.O.

Funding: This study was funded by the Spanish Ministry of Science and Innovation (MICINN) and the Carlos III Health Institute/European Regional Development Fund (ERDF) (FIS: PI13/00618, PI13/01526, PI13/00058, PI13/01635, PI13/02528, PI12/01474; RETICS: RD12/0005, RD16/0007), the Regional Health Administration of Castilla and León (GRS 1191/B/15, GRS 909/B/14, GRS 770/B/13) and the Infosalud Foundation. None of the funders were involved in the design, implementation, analysis or interpretation of the data.

Acknowledgments: Membership of the EVIDENT Investigators Group:

1. Coordinating centre: La Alamedilla Health Center (Health Service of Castilla y León): Luis Garcia-Ortiz, Jose I Recio-Rodriguez, Manuel A. Gómez-Marcos, Emiliano Rodríguez-Sánchez, Jesus Gonzalez-Sanchez, Jose A Maderuelo-Fernández, Jose A Iglesias-Valiente, Maria C Patino-Alonso, Diana Pérez-Arechaederra, Sara Mora-Simón, Cristina Agudo-Conde, Maria C Castaño-Sánchez, Carmela Rodríguez-Martín, Benigna Sánchez-Salgado, Angela de Cabo-Laso, Rosario Alonso-Domínguez, and Natalia Sánchez-Aguadero.

2. Collaborating centres: Passeig de Sant Joan Health Center (Catalan Health Service): Carlos Martín-Cantera, Jose Canales-Reina, Epifania Rodrigo de Pablo, Maria L Lasaosa-Medina, Maria J Calvo-Aponte, A Rodríguez-Franco, Carmen Martin-Borras, Anna Puig-Ribera, Ruben Colominas-Garrido, and Elisa Puigdomenech Puig.

3. Ca N'Oriac Health Centre (Catalan Health Service): Monserrat Romaguera-Bosch.

4. Sant Roc Health Centre (Catalan Health Service): Sandra Maneus.

5. Río Tajo Health Centre (Health Service of Castilla-La Mancha): Yolanda Schmolling-Guinovart, Beatriz Rodríguez-Martín, Alicia Fernández del Rio, José A Fernández-Díaz, José B Calderón-Ubeda, José L Menéndez-Obregón, Antonio Segura-Fragoso, Carmen Zabala-Baños, Vicente Martínez-Vizcaíno, and María Martínez-Andrés.

6. Casa de Barco Health Centre (Health Service of Castilla y León): Maria C Fernández-Alonso, Amparo Gómez-Arranz, Aventina de la Cal de la Fuente, Marta Menéndez-Suarez, Irene Repiso-Gento.

7. San Pablo Health Centre (Health Service of Castilla y León): Maria I Arranz-Hernando, Maria I Pérez-Concejo, Maria A Alonso-Manjarres, Maria E Villarroya, Maria J Arribas de Rodrigo, Margarita Pérez de Lis, Maria D de Arriba-Gómez, A Arqueaga-Luengo and Maria M López-Arroyo. 
8. Torre Ramona Health Centre (Health Service of Aragón): Natividad González-Viejo, Jose F Magdalena-Belio, Luis Otegui-Ilarduya, Francisco J Rubio-Galán, Amor Melguizo-Bejar, Ines Sauras-Yera, Maria J Gil-Train, Marta Iribarne-Ferrer, Olga Magdalena-González, and Miguel A Lafuente-Ripolles.

9. Primary Care Research Unit of Bizkaia (Basque Health Service-Osakidetza): Gonzalo Grandes, Álvaro Sanchez, Verónica Arce, Maria S Arietaleanizbeaskoa, Nere Mendizabal, and Eguskiñe Iturregui-San Nicolas.

10. 10. CGB Computer Company, Salamanca, Spain (contribution to technical development of the EVIDENT II application).

Conflicts of Interest: The authors declare that they have no competing interests.

Availability of Data and Material: The datasets used and/or analysed during the current study are available from the corresponding author on reasonable request.

\section{References}

1. Hu, F.B. Dietary pattern analysis: A new direction in nutritional epidemiology. Curr. Opin. Lipidol. 2002, 13, 3-9. [CrossRef] [PubMed]

2. Martinez-Gonzalez, M.A.; Bes-Rastrollo, M. Dietary patterns, Mediterranean diet, and cardiovascular disease. Curr. Opin. Lipidol. 2014, 25, 20-26. [CrossRef]

3. Martinez-Gonzalez, M.A.; Martin-Calvo, N. Mediterranean diet and life expectancy; beyond olive oil, fruits, and vegetables. Curr. Opin. Clin. Nutr. Metab. Care 2016, 19, 401-407. [CrossRef]

4. Martinez-Lacoba, R.; Pardo-Garcia, I.; Amo-Saus, E.; Escribano-Sotos, F. Mediterranean diet and health outcomes: A systematic meta-review. Eur. J. Public Health 2018, 28, 955-961. [CrossRef]

5. Martinez-Gonzalez, M.A.; Salas-Salvado, J.; Estruch, R.; Corella, D.; Fito, M.; Ros, E. Benefits of the Mediterranean Diet: Insights From the PREDIMED Study. Prog. Cardiovasc. Dis. 2015, 58, 50-60. [CrossRef]

6. Ros, E.; Martinez-Gonzalez, M.A.; Estruch, R.; Salas-Salvado, J.; Fito, M.; Martinez, J.A.; Corella, D. Mediterranean diet and cardiovascular health: Teachings of the PREDIMED study. Adv. Nutr. 2014, 5, S330-S336. [CrossRef]

7. Agodi, A.; Maugeri, A.; Kunzova, S.; Sochor, O.; Bauerova, H.; Kiacova, N.; Barchitta, M.; Vinciguerra, M. Association of Dietary Patterns with Metabolic Syndrome: Results from the Kardiovize Brno 2030 Study. Nutrients 2018, 10, 898. [CrossRef]

8. Maugeri, A.; Kunzova, S.; Medina-Inojosa, J.R.; Agodi, A.; Barchitta, M.; Homolka, M.; Kiacova, N.; Bauerova, H.; Sochor, O.; Lopez-Jimenez, F.; et al. Association between eating time interval and frequency with ideal cardiovascular health: Results from a random sample Czech urban population. Nutr. Metab. Cardiovasc. Dis. 2018, 28, 847-855. [CrossRef] [PubMed]

9. Salas-Salvado, J.; Becerra-Tomas, N.; Garcia-Gavilan, J.F.; Bullo, M.; Barrubes, L. Mediterranean Diet and Cardiovascular Disease Prevention: What Do We Know? Prog. Cardiovasc. Dis. 2018, 61, 62-67. [CrossRef] [PubMed]

10. Talaei, M.; Koh, W.P.; Yuan, J.M.; van Dam, R.M. DASH Dietary Pattern, Mediation by Mineral Intakes, and the Risk of Coronary Artery Disease and Stroke Mortality. J. Am. Heart Assoc. 2019, 8, e011054. [CrossRef] [PubMed]

11. Chiavaroli, L.; Viguiliouk, E.; Nishi, S.K.; Blanco Mejia, S.; Rahelic, D.; Kahleova, H.; Salas-Salvado, J.; Kendall, C.W.; Sievenpiper, J.L. DASH Dietary Pattern and Cardiometabolic Outcomes: An Umbrella Review of Systematic Reviews and Meta-Analyses. Nutrients 2019, 11, 338. [CrossRef] [PubMed]

12. Djousse, L.; Ho, Y.L.; Nguyen, X.T.; Gagnon, D.R.; Wilson, P.W.F.; Cho, K.; Gaziano, J.M. DASH Score and Subsequent Risk of Coronary Artery Disease: The Findings From Million Veteran Program. J. Am. Heart Assoc. 2018, 7. [CrossRef] [PubMed]

13. Vaz Velho, M.; Pinheiro, R.; Rodriguez, S. The Atlantic Diet-Origin and features. Int. J. Food Stud. 2016, 5, 106-119. [CrossRef]

14. Oliveira, A.; Lopes, C.; Rodriguez-Artalejo, F. Adherence to the Southern European Atlantic Diet and occurrence of nonfatal acute myocardial infarction. Am. J. Clin. Nutr. 2010, 92, 211-217. [CrossRef] [PubMed]

15. Guallar-Castillon, P.; Oliveira, A.; Lopes, C.; Lopez-Garcia, E.; Rodriguez-Artalejo, F. The Southern European Atlantic Diet is associated with lower concentrations of markers of coronary risk. Atherosclerosis 2013, 226, 502-509. [CrossRef] [PubMed] 
16. Recio-Rodriguez, J.I.; Martin-Cantera, C.; Gonzalez-Viejo, N.; Gomez-Arranz, A.; Arietaleanizbeascoa, M.S.; Schmolling-Guinovart, Y.; Maderuelo-Fernandez, J.A.; Perez-Arechaederra, D.; Rodriguez-Sanchez, E.; Gomez-Marcos, M.A.; et al. Effectiveness of a smartphone application for improving healthy lifestyles, a randomized clinical trial (EVIDENT II): Study protocol. BMC Public Health 2014, 14, 254. [CrossRef] [PubMed]

17. Fernandez-Ballart, J.D.; Pinol, J.L.; Zazpe, I.; Corella, D.; Carrasco, P.; Toledo, E.; Perez-Bauer, M.; Martinez-Gonzalez, M.A.; Salas-Salvado, J.; Martin-Moreno, J.M. Relative validity of a semi-quantitative food-frequency questionnaire in an elderly Mediterranean population of Spain. Br. J. Nutr. 2010, 103, 1808-1816. [CrossRef]

18. Calvo-Malvar Mdel, M.; Leis, R.; Benitez-Estevez, A.J.; Sanchez-Castro, J.; Gude, F. A randomised, family-focused dietary intervention to evaluate the Atlantic diet: The GALIAT study protocol. BMC Public Health 2016, 16, 820. [CrossRef] [PubMed]

19. Tojo, R.; Leis, R. El papel de la Dieta Atlantica como contrapunto saludable a la Dieta Ocidental actual. In $\mathrm{La}$ Dieta Atlantica, el Pescado y Las algas-Su Importancia en el Neurodesarrollo y la Funcion Cerebral; Fundacion Dieta Atlantica and Universidade de Santiago de Compostela: Santiago de Compostela, Spain, 2009; pp. $23-28$.

20. Melanson, E.L., Jr.; Freedson, P.S. Validity of the Computer Science and Applications, Inc. (CSA) activity monitor. Med. Sci. Sports Exerc. 1995, 27, 934-940. [CrossRef] [PubMed]

21. O’Brien, E.; Asmar, R.; Beilin, L.; Imai, Y.; Mancia, G.; Mengden, T.; Myers, M.; Padfield, P.; Palatini, P.; Parati, G.; et al. Practice guidelines of the European Society of Hypertension for clinic, ambulatory and self blood pressure measurement. J. Hypertens. 2005, 23, 697-701. [CrossRef]

22. Mancia, G.; Fagard, R.; Narkiewicz, K.; Redán, J.; Zanchetti, A.; Böhm, M.; Christiaens, T.; Cifkova, R.; De Backer, G.; Dominiczak, A.; et al. Practice guidelines for the management of arterial hypertension of the European Society of Hypertension (ESH) and the European Society of Cardiology (ESC): ESH/ESC Task Force for the Management of Arterial Hypertension. J. Hypertens. 2013, 31, 1925-1938. [CrossRef] [PubMed]

23. Chamberlain, J.J.; Rhinehart, A.S.; Shaefer, C.F., Jr.; Neuman, A. Diagnosis and Management of Diabetes: Synopsis of the 2016 American Diabetes Association Standards of Medical Care in Diabetes. Ann. Intern. Med. 2016, 164, 542-552. [CrossRef]

24. D’Agostino, R.B., Sr.; Vasan, R.S.; Pencina, M.J.; Wolf, P.A.; Cobain, M.; Massaro, J.M.; Kannel, W.B. General cardiovascular risk profile for use in primary care: The Framingham Heart Study. Circulation 2008, 117, 743-753. [CrossRef]

25. Gorostegi-Anduaga, I.; Maldonado-Martin, S.; MartinezAguirre-Betolaza, A.; Corres, P.; Romaratezabala, E.; Whittaker, A.C.; Francisco-Terreros, S.; Perez-Asenjo, J. Effects on Cardiovascular Risk Scores and Vascular Age After Aerobic Exercise and Nutritional Intervention in Sedentary and Overweight/Obese Adults with Primary Hypertension: The EXERDIET-HTA Randomized Trial Study. High Blood Press. Cardiovasc. Prev. 2018, 25, 361-368. [CrossRef]

26. Salas-Salvado, J.; Rubio, M.A.; Barbany, M.; Moreno, B. SEEDO 2007 Consensus for the evaluation of overweight and obesity and the establishment of therapeutic intervention criteria. Med. Clin. 2007, 128, 184-196.

27. Bergman, R.N.; Stefanovski, D.; Buchanan, T.A.; Sumner, A.E.; Reynolds, J.C.; Sebring, N.G.; Xiang, A.H.; Watanabe, R.M. A better index of body adiposity. Obesity 2011, 19, 1083-1089. [CrossRef] [PubMed]

28. Van Bortel, L.M.; Laurent, S.; Boutouyrie, P.; Chowienczyk, P.; Cruickshank, J.K.; De Backer, T.; Filipovsky, J.; Huybrechts, S.; Mattace-Raso, F.U.; Protogerou, A.D.; et al. Expert consensus document on the measurement of aortic stiffness in daily practice using carotid-femoral pulse wave velocity. J. Hypertens. 2012, 30, 445-448. [CrossRef]

29. Schroder, H.; Fito, M.; Estruch, R.; Martinez-Gonzalez, M.A.; Corella, D.; Salas-Salvado, J.; Lamuela-Raventos, R.; Ros, E.; Salaverria, I.; Fiol, M.; et al. A short screener is valid for assessing Mediterranean diet adherence among older Spanish men and women. J. Nutr. 2011, 141, 1140-1145. [CrossRef] [PubMed]

30. Sanchez-Villegas, A.; Alvarez-Perez, J.; Toledo, E.; Salas-Salvado, J.; Ortega-Azorin, C.; Zomeno, M.D.; Vioque, J.; Martinez, J.A.; Romaguera, D.; Perez-Lopez, J.; et al. Seafood Consumption, Omega-3 Fatty Acids Intake, and Life-Time Prevalence of Depression in the PREDIMED-Plus Trial. Nutrients 2018, 10, 2000. [CrossRef] [PubMed]

31. Paz-Graniel, I.; Babio, N.; Mendez, I.; Salas-Salvado, J. Association between Eating Speed and Classical Cardiovascular Risk Factors: A Cross-Sectional Study. Nutrients 2019, 11, 83. [CrossRef] [PubMed] 
32. He, K. Fish, long-chain omega-3 polyunsaturated fatty acids and prevention of cardiovascular disease-Eat fish or take fish oil supplement? Prog. Cardiovasc. Dis. 2009, 52, 95-114. [CrossRef] [PubMed]

33. Ben-Shlomo, Y.; Spears, M.; Boustred, C.; May, M.; Anderson, S.G.; Benjamin, E.J.; Boutouyrie, P.; Cameron, J.; Chen, C.H.; Cruickshank, J.K.; et al. Aortic pulse wave velocity improves cardiovascular event prediction: An individual participant meta-analysis of prospective observational data from 17,635 subjects. J. Am. Coll. Cardiol. 2014, 63, 636-646. [CrossRef] [PubMed]

34. Kowalkowska, J.; Slowinska, M.A.; Slowinski, D.; Dlugosz, A.; Niedzwiedzka, E.; Wadolowska, L. Comparison of a full food-frequency questionnaire with the three-day unweighted food records in young Polish adult women: Implications for dietary assessment. Nutrients 2013, 5, 2747-2776. [CrossRef]

35. Thompson, F.E.; Byers, T. Dietary assessment resource manual. J. Nutr. 1994, 124, S2245-S2317. [CrossRef]

36. Recio-Rodriguez, J.I.; Rodriguez-Martin, C.; Gonzalez-Sanchez, J.; Rodriguez-Sanchez, E.; Martin-Borras, C.; Martinez-Vizcaino, V.; Arietaleanizbeaskoa, M.S.; Magdalena-Gonzalez, O.; Fernandez-Alonso, C.; Maderuelo-Fernandez, J.A.; et al. EVIDENT Smartphone App, a New Method for the Dietary Record: Comparison With a Food Frequency Questionnaire. JMIR mHealth uHealth 2019, 7, e11463. [CrossRef] [PubMed]

(C) 2019 by the authors. Licensee MDPI, Basel, Switzerland. This article is an open access article distributed under the terms and conditions of the Creative Commons Attribution (CC BY) license (http://creativecommons.org/licenses/by/4.0/). 